\title{
ANOTAÇÕES ACERCA DA QUESTÃO URBANA CONTEMPORÂNEA
}

\author{
APUNTES ACERCA DE LA CUESTIÓN URBANA CONTEMPORÁNEA
}

\author{
NOTES ON THE CONTEMPORARY URBAN QUESTION
}

\section{RÉFLEXIONS AUTOUR DE LA QUESTION URBAINE CONTEMPORAINE}

DOI: 10.5533/1984-2503-20135105

\section{Cezar Honorato ${ }^{1}$}

\section{RESUMO}

Este artigo enfoca a historia da ideia de cidade e a história da questão urbana a partir das interpretações mais referidas no campo das ciências humanas e sociais (História, Economia e Ciências Sociais). Tem em vista uma análise das principais tendências e suas confrontações.

Palavras-chaves: ideia de cidade, questão urbana, historiografia.

\section{RESUMEN}

Este artículo enfoca la historia de la idea de ciudad y la historia de la cuestión urbana a partir de las interpretaciones más referidas en el campo de las ciencias humanas y sociales (Historia, Economía y Ciencias Sociales). El objetivo es desarrollar un análisis de las principales tendencias y sus confrontaciones.

Palabras clave: idea de ciudad, cuestión urbana, historiografía.

\section{ABSTRACT}

This article focuses on the history of the idea of a city and the history of the urban question based on the most cited interpretations in the field of human and social sciences (History, Economics and Social Sciences). It features an analysis of the prevailing trends and their points of contention.

Key words: the idea of a city, the urban question, historiography.

\footnotetext{
${ }^{1}$ Professor Associado do Departamento de História da Universidade Federal Fluminense. Doutor em História Econômica (USP) e autor de vários artigos no Brasil e no Exterior.

E-mail: cezarhonorato@gmail.com.
} 


\section{RÉSUMÉ}

Cet article analysera l'histoire du concept de ville et celle de la question urbaine à partir des interprétations les plus en vue du champ des sciences humaines et sociales (histoire, économie et sciences sociales). L'objectif est ici d'étudier les principales tendances et de les confronter.

Mots-clés: concept de ville, question urbaine, historiographie.

Nos últimos dois séculos, assistimos a um crescimento exponencial da vida urbana. A previsão do UN-HABITAT realizada em 2006 é de que até 2030, o número de pessoas morando em cidades deverá atingir um montante de quase 5 bilhões de pessoas, correspondendo a cerca de $81 \%$ da população mundial. No caso brasileiro, a região Sudeste apresentava já em 2006, 92,1\% de sua população nas áreas urbanas. No caso do Estado do Rio de Janeiro, de uma população total de 15.989 .929 - segundo o censo de 2010 - temos 15.464.239 habitando nas áreas urbanas, ou seja, quase 100\%! Mais do que nunca, a questão urbana se coloca como uma demanda para os historiadores neste alvorecer do século XXI.

Sempre cabe a observação metodológica de que para o IBGE a população urbana é aquela residente no interior do perímetro urbano, sendo a população rural aquela que está fora do perímetro urbano. Contudo, toda sede de município é considerada como área urbana, independentemente de suas características ou mesmo de conter outros núcleos urbanos num mesmo município. Além disso, muitos municípios interessados em aumentar a seu perímetro urbano e, com isso, a sua base tributária - somente o território urbano é totalmente tributável pelo poder municipal - elevam à categoria de área urbana, áreas rurais e peri-urbanas.

Estas questões estão normalmente mais afeitas aos geógrafos e sociólogos de ofício. Contudo, para nós, historiadores, interessa muito de perto a formação histórica desse mundo urbano capitalista, bem como a sua configuração e dinâmica ao longo do tempo, sem que isso signifique dar menor atenção às características de seu território ou o seu perfil social nos dias de hoje. 
Existe uma grande tradição de estudos sobre a história das cidades feita por historiadores, sociólogos, arquitetos, geógrafos, etc. ${ }^{2}$. Com perspectivas diferenciadas, tais estudos tem nos ajudado muito no entendimento da vida urbana. Dentre as referências fundamentais entre os historiadores brasileiros, tornou-se obrigatório citar o debate de Caio Prado Jr., em seu livro Evolução Política do Brasil e no de Sergio Buarque de Holanda em Raízes do Brasil, considerando as cidades coloniais brasileiras; e mais recentemente, brilhantemente analisado em artigo de Fania Fridman ${ }^{3}$.

Se recuperarmos o primado de que a história é a relação que os indivíduos mantém entre si e com o território no tempo - parafraseando a clássica perspectiva exposta por Marx e Engels na Ideologia Alemã $\tilde{~}^{4}$ temos que as cidades surgem e se transformam por força dessas relações sociais materializadas num território. De outro modo, o território urbano é produtor e produto das relações sociais ali existentes num determinado momento do tempo, no qual a sociedade e cada indivíduo de per si, inscreve suas demandas, projetos e estilo de viver, sentir e pensar. Logo, fazem a história, embora não como querem...

Mais do que agregação de pessoas num território compacto e contíguo - traços minimamente comuns de qualquer cidade - o território urbano deve ser entendido como a relação que os indivíduos e as classes constroem especificamente com os demais, num território ao longo do tempo.

Alguns analistas apressados buscam comparações entre cidades considerando características gerais, esquecendo as peculiaridades de cada formação territorial-social urbana e daí, extraem conclusões impressionistas.

Um exemplo pode ser a suposição de que a construção de altos muros nos condomínios fechados das principais cidades brasileiras as tornaria assemelhadas aos burgos medievais e seus muros, como se o estilo de vida, a dinâmica de classes, as formas de apropriação do território urbano, tudo o mais que subjaz aos dois exemplos, fossem análogos.

Mesmo o medo, é historicamente diferente: se no medievo o medo estava assentado principalmente na ameaça de invasões e doenças, nos tempos de hoje é marcadamente referente à violência urbana sobre as pessoas e as coisas.

\footnotetext{
${ }^{2}$ A este respeito, ver Barros, José D’Assunção (2007). Cidade e História, Petrópolis: Vozes.

3 Prado Jr., Caio (1947). Evolução Política do Brasil, 2. ed., São Paulo: Brasiliense; Holanda, Sergio Buarque (1987). Raízes do Brasil, 19. ed., Rio de Janeiro: J. Olympio; e, Fridman, Fania (2010). "Breve História do Debate sobre a Cidade Colonial Brasileira”. In Fridman, Fania e Abreu, Maurício (2010). Cidades Latino-Americanas, Rio de Janeiro: FAPERJ/Casa da Palavra.

${ }^{4}$ Marx, Karl e Engels, Friedrich (2007). A Ideologia Alemã, São Paulo: Boitempo.
} 
Mesmo quando consideramos globalmente o desenvolvimento das cidades na Europa, temos que ter nítido que desde a transição feudal-capitalista e a formação dos estados nacionais, as cidades europeias foram se transformando em centros de poder político e social e reafirmando o seu papel de centro de comercialização de produtos: enfim, transformando-se em mercado!

Já no caso latino-americano, se grandes núcleos urbanos pré-existiam na América Hispânica quando da chegada do colonizador, o processo de conquista e colonização redefiniu o sentido destas cidades visando atender às novas demandas derivadas do Antigo Sistema Colonial Mercantilista. Talvez o mais expressivo exemplo seja o da cidade do México - Tenoctitlan - que funcionava tanto como grande centro do domínio azteca como mercado de uma vasta rede comercial.

No Brasil, podemos observar um fenômeno curioso: a transformação dos núcleos indígenas existentes nas áreas litorâneas em aldeamento, sob a tutela da Igreja, como forma de garantir a oferta de mão-de-obra local nos primeiros tempos coloniais, além de produzirem alimentos para os primeiros núcleos urbanos responsáveis pela articulação com a metrópole, que eram instalados.

As vilas surgiram devido a uma tríplice demanda:

a) a de serem locais de agregação de produtos a serem enviados à Metrópole;

b) como portas de entrada para os produtos oriundos do exterior; e,

c) como núcleos de articulação entre o litoral e o interior da colônia. Neste sentido, funcionavam como centros de articulação com a metrópole dos produtos de importação e exportação; centros do domínio metropolitano; centros de abastecimento dos sertões ou de reabastecimento das embarcações.

Ressalve-se que, excetuando-se talvez Rio de Janeiro ${ }^{5}$, Salvador, Santos e Recife ao final do século XVII, não se pode falar de uma vida urbana colonial, já que a maioria daquilo que alguns chamam de cidades não passavam de pequenas vilas, arraiais e arrabaldes.

Ao longo do século seguinte, este cenário começa a mudar com a questão da extração de ouro e pedras preciosas nas Minas Gerais - uma atividade predominantemente urbana - e de centros de abastecimento à região mineira, particularmente de gado. A essa altura, Salvador, São Paulo e Rio de Janeiro já rivalizavam como polos de abastecimento do interior e, particularmente o Rio de Janeiro, como centro das exportações para a metrópole.

\footnotetext{
${ }^{5}$ Abreu, Mauricio de Paiva (2010). Geografia Histórica do Rio de Janeiro, Rio de Janeiro: Andrea Jacobson.
} 
Ressalve-se que, o crescimento da malha urbana dessas cidades coloniais seguia a lógica das cidades portuguesas, particularmente o projeto emergido das reformas urbanas realizadas após o terremoto e o grande incêndio de Lisboa ocorrido no período pombalino.

\section{1 - A Cidade Capitalista}

A Revolução Industrial ocorrida na Inglaterra a partir da segunda metade do século XVIII, ao marcar a implantação definitiva da lógica do capital sobre toda a sociedade, redefiniu o próprio sentido das cidades, a sua configuração, a sua dinâmica, etc.

Novas demandas surgiram relacionadas à utilização do território que passou a ser parte integrante da nova dinâmica na condição de produto, produtor e reprodutor do capital gerando uma lógica urbana diferenciada: a lógica capitalista ${ }^{6}$.

Entendemos como lógica urbana capitalista aquela que virtualiza o capital e subverte as antigas formas de viver, de pensar e agir nitidamente vinculadas às relações sociais do tipo antigo, adequando-as às novas demandas da sociedade dentre elas e, fundamentalmente, a transformação do território em mercadoria. Além disso, viabiliza o aumento da maior rapidez de circulação de mercadorias, inclusive a mercadoria trabalho.

Não se trata de um processo pacífico. Assim como o processo de trabalho sob a nova ordem, o surgimento da cidade capitalista foi um processo de conflitos, adaptações e subsunção de relações sociais daquelas do tipo antigo. Também com relação à apropriação do território urbano, temos processos de superação de formas pretéritas de ocupação territorial, através da subsunção destas através do conflito, da acomodação ou da adaptação, além da convivência do novo com o antigo.

Este é um processo típico da urbanização que não se confunde com o da cidade. Pois que a cidade é onde territorialmente se materializam as relações sociais. A cidade é o locus, o território, onde o processo de urbanização se torna concreto. E, como tal, precisa se adaptar à nova lógica.

No capitalismo, a produção expande-se espacial e socialmente (no sentido que penetra toda a sociedade), incorporando todas as atividades do homem e redefinindo-se sob a lógica do processo de valorização do capital - o espaço tornado mercadoria sob a lógica do capital fez com que o uso (acesso necessário à realização da vida), fosse redefinido pelo valor de troca. A produção do espaço

\footnotetext{
6 Neste sentido, ver Harvey, David (2006). A Produção Capitalista do Espaço, 2. ed., São Paulo: Annablume/HUCITEC e Lefebvre, Henri (1999). A Cidade do Capital, Rio de Janeiro: DP\&A.
} 
se insere na lógica da produção capitalista que transforma toda a produção em mercadoria. $^{7}$

A primeira e fundamental demanda é de transformar todo o território em mercadoria a ser valorada, comprada e vendida no mercado, e, obviamente, apropriada de forma privada, como convém numa sociedade burguesa.

Em segundo lugar, este novo modelo de cidade deve viabilizar a ampliação da taxa de lucro do capital para permitir o menor custo de rotação e de efetivação das mercadorias, inclusive e principalmente, da mercadoria trabalho.

Henri Lefebvre comentando as preocupações de Marx acerca das cidades em seus raros momentos a tratar do tema, aponta nos Grundisse:

[...] O campo, em oposição à cidade, é a dispersão e o isolamento. A cidade, por outro lado, concentra não só a população, mas os instrumentos de produção, o capital, as necessidades, os prazeres. Logo, tudo o que faz com que uma sociedade seja uma sociedade. É assim porque "a existência da cidade implica simultaneamente a necessidade da administração, da polícia, dos impostos etc., em uma palavra, a necessidade de organização comunal, portanto da política em geral. $^{8}$

Contudo, temos que ter em conta as considerações de Sandra Cristina Ferreira:

Em sua natureza, a cidade não é produto da economia capitalista, e está presente enquanto aglomeração humana, com funções e formas construídas segundo diferentes influências políticas e econômicas, culturais ou religiosas no decorrer do tempo histórico. Entretanto, é real que sua existência ganhou força e maior significado enquanto rede de cidades com o modo de produção vigente e, desde a fase pré-capitalista era possível vislumbrar que a cidade assumia novo posicionamento na reorganização do espaço sócio-produtivo. ${ }^{9}$

Senão, como podemos explicar a existência e a vitalidade de importantíssimas cidades seculares se apenas consideramos a questão da cidade capitalista? $\mathrm{O}$ que estamos querendo mostrar é que não se pode confundir história urbana com história de certa cidade. O que reafirmamos é que, na análise específica de uma cidade ou um bairro, podemos perceber o processo de expansão da lógica do capital, destruindo territórios, redefinido utilidades e/ou significados para as suas pretéritas formas de relações sócio-territoriais.

\footnotetext{
7 Carlos, Ana Fani (2011). "Da Organização à Produção do Espaço no Movimento do Pensamento Geográfico". In Carlos, Ana Fani et al. (Orgs.) (2011). A Produção do Espaço Urbano, São Paulo: Contexto, p. 60

${ }^{8}$ Lefebvre, H. (1999). Op. Cit., p. 49.

9 Ferreira, Sandra Cristina (2008). "Urbanização E Rede Urbana Brasileira: Orientação Teórica e Metodológica Preliminar". In I Simpósio de Pós-Graduação em Geografia do Estado de São Paulo, Rio Claro: UNESP, p. 537.
} 
Seguindo na mesma linha, temos a questão da especificidade de cada cidade. Cada cidade - assim como cada fração de seu território - apresenta características do processo mais geral da urbanização capitalista. Apresenta também, características específicas e não redutíveis frutos das relações dos seus agentes históricos, naquele território, durante certo tempo.

Não é por outra razão que Eloísa Petti Pinheiro é categórica:

A observação nos ensina que as cidades são distintas entre si e dentro de si. Cada trecho de cidade tem seu traçado, sua trama, sua característica e sua história. A combinação de muitos fatores faz com que elas tenham seu próprio caráter, seus signos, seus símbolos e seus sinais, indicadores das mudanças ocorridas em anos ou séculos anteriores e reveladores de sua história. Em suma, a cidade é o reflexo do tempo, das ideologias, das políticas e da sociedade. ${ }^{10}$

Sandra Pesavento avança na mesma direção ao nos afirmar que,

A modificação do espaço de uma cidade, dando a ela forma e feição, contém em si um projeto político de gerenciamento do urbano em sua totalidade. É, por um lado, uma tarefa de profissionais especificamente habilitados para tal - urbanistas, arquitetos, engenheiros - mas também comporta o que se poderia chamar de intervenção do cotidiano. Ou seja, esse espaço sonhado, desejado, batalhado elou imposto é, por sua vez, também reformulado, vivido e descaracterizado pelos ${ }_{11}$ habitantes da rua, que, a seu turno, o requalificam e lhe conferem novos sentidos.

O trecho reproduzido anteriormente, nos remete a outras duas questões metodológicas importantíssimas para podermos avançar tanto ao buscarmos uma história urbana, quanto trabalhamos com a história de uma cidade específica ou de um bairro.

O primeiro desafio que se coloca para nós é, se a cidade, particularmente a capitalista contemporânea, materializa as múltiplas determinações da sociedade: como apreendê-la na sua totalidade? Assim como em qualquer retorno da realidade, temos que perceber as múltiplas determinações entre o território, o tempo longo e o tempo curto. Como nenhuma ciência é capaz de dar conta de tudo ao mesmo tempo, devemos aprofundar a discussão acerca da transdisciplinaridade, além da necessidade de estudos comparativos. Segundo Stella Bresciani,

Buscar a formação desse saber exige (...) que renunciemos a um percurso único ou a uma relação de causa e efeito linear. É minha convicção que, sem abdicar das noções marxistas de determinação, de infraestrutura e superestrutura, de ideologia, pode-se acatar a sugestiva proposta de Michel Foucault que nos diz que, mais do que a origem de um saber, o que nos proporciona pontos de apoio é

\footnotetext{
${ }^{10}$ Pinheiro, Eloisa Petti (2002). Europa, França e Bahia: Difusão e adaptação de Modelos Urbanos (Paris, Rio e Salvador), Salvador: UFBA, p. 24.

${ }^{11}$ Pesavento, Sandra Jatahy (1999). O Imaginário da Cidade, Porto Alegre: UFRGS, p. 16.
} 
a busca dos começos. Começos no plural. Isso implica afirmar que considero insuficiente tomar como origem a industrialização - aumento da densidade demográfica nas cidades aliado a modificações no processo de trabalho na sequência -, artesanato, manufatura e grande indústria fabril. O saber que se forma é tributário de vários outros saberes, que, situados em campos diversos, num dado momento como que enfeixam um saber multifacetado sobre a cidade. ${ }^{12}$

Observemos com atenção que Stella Bresciani, em nenhum momento, nega a importância fundamental de se perceber as relações mais profundas e estruturais da sociedade na recuperação da história das cidades. O que a autora nos pede é para atentarmos para outras dimensões humanas que também são fundamentais na formação e desenvolvimento de uma cidade; além de outros saberes construídos por outros profissionais acerca dela e que nela interferem.

A segunda grande questão metodológica se desdobra em vários aspectos. Comecemos pela perspectiva de que toda cidade sempre é incompleta, estando o tempo todo num processo de fazer-se, de reinventar-se, de reconstruir-se, particularmente se pensarmos na aceleração do tempo, fruto da sociedade contemporânea capitalista. A todo o momento e de forma cada vez mais acelerada, a urbe sofre intervenções de todo o tipo tanto aqueles executadas pelo poder público, como as executadas pelos entes privados individualmente ou em grupo.

Na mesma linha de raciocínio, temos a questão da "falta de ordem urbana" ou regras e padrões perenes e estáveis de comportamento social no território. Isto porque, como parte integrante da lógica capitalista, a cidade é também a "anarquia da produção" e de conflitos entre os múltiplos interesses privados.

Mais ainda, contraditoriamente ao fato de que a grande marca da urbanização capitalista ser a grande concentração populacional em territórios exíguos, a tendência da dinâmica social das grandes cidades contemporâneas é a da atomização dos indivíduos o individualismo possessivo - tão bem descrito já na década de 1840 por Engels ${ }^{13}$ ao refletir acerca das metrópoles e a situação da classe trabalhadora na Inglaterra.

Tais questões anteriormente elencadas nos colocam desafios teóricometodológicos de grande monta. Infelizmente, podemos avançar muito pouco neste momento embora seja de extrema importância, e apontarmos os limites e dificuldades enfrentadas pelos pesquisadores da história urbana.

\footnotetext{
${ }^{12}$ Bresciani, Maria Stella (2002). "Cidade e história”. In Oliveira, Lucia Lippi (Org.) (2002). Cidade: história e desafios, Rio de Janeiro: Ed. FGV, p. 19

${ }_{13}$ Engels, Frederic (1975). A Situação da Classe Trabalhadora na Inglaterra, Porto: Apontamento.
} 
Dando segmento as nossas reflexões, devemos ficar atentos à construção da cotidianidade nas cidades contemporâneas. Nunca é demais afirmar que é no cotidiano, no vivido, que as pessoas se relacionam entre si e com o território. No espaço urbanao, as grandes questões se manifestam na vivência diária de cada ser individual e coletivamente.

Conforme afirmado anteriormente, a implantação da chamada sociedade capitalista, a partir do final do século XVIII e início do século XIX muda a maneira de se viver, mudando qualitativamente as relações entre os indivíduos e o território. Nas sociedades pré-capitalistas tínhamos o primado das relações sociais do tipo simples, pessoalizadas. Após a disseminação da sociedade burguesa capitalista, tais relações passam a ser mediadas pelo capital, pela ideia do lucro, pela ideia do trabalho remunerado, pela mercadorização das relações sociais.

E como se caracterizam essas relações? Basicamente, ocorre aquilo que as ciências sociais de tradição marxista chamam de alienação do ser social. Ou seja: dentro do cotidiano do mundo do trabalho a pessoa, o indivíduo, o ser social, só serve, só é valorizado, só tem sentido, enquanto força de trabalho. Enquanto se é capaz de trabalhar, produzir lucro, etc., se tem valia. Na hora que a pessoa perde a capacidade de produzir lucro, de produzir e consumir mercadorias vira "supérfluo", descartável.

De outro modo, as dimensões do sonhar, do pensar, do viver, do delirar, do gostar, ou do odiar, não têm valor, exceto se mediados pelo mundo da mercadoria. Reafirma-se, a cada dia, a lição aprendida em casa desde criança: local de trabalho não pode se confundir com vida pessoal. Você não pode misturar trabalho com amor, trabalho com paixão.

Contudo, se observarmos com mais acuidade, perceberemos que mais da metade da nossa vida - para não dizer quase dois terços - é vivenciado num território específico, o mundo do trabalho. Logo, a alienação do ser social faz com que esse indivíduo - que é uma totalidade, é um ser humano, que é corpo e alma, tem anima - quando se insere no mundo do trabalho ele só é percebido, valorizado, aceito e recompensado, enquanto força de trabalho.

As outras dimensões do ser humano perdem sentido nas relações sociais e isso gera a fragmentação da pessoa. Não é por coincidência que algumas doenças mentais somente passaram a existir após a implantação da sociedade capitalista, visto que elas se originam exatamente do mundo do trabalho e do processo de deslocamento necessário para este território, o local de trabalho. 
Essa mesma sociedade que fragmenta e que aliena, constrói a visão da pessoa, do indivíduo comum, que transforma este homem simples em alguém fragmentado, em alguém que tem muita dificuldade de entender criticamente a sua realidade, de se encontrar na sua existência.

Embora possa parecer contraditório, essa mesma sociedade capitalista que aliena e fragmenta, criou a Modernidade. Destarte, paralelamente a implantação da superexploração da força de trabalho, foi historicamente sendo implantada a modernidade, que se materializa na liberdade - a liberdade como valor universal, acabando com as escravidões, com as servidões, com as outras formas subjugadoras do indivíduo, com as limitações aos deslocamentos na urbe -; com a desigualdade jurídica, ou seja, todos são juridicamente iguais; e garantindo o acesso a bens e serviços públicos. O nome para isto é cidadania!

Isso implica em dizer que se construiu nos países de capitalismo central - através, obviamente de várias lutas sociais - a cidadania com certo ordenamento jurídico que garantia a cidadania formal e, obviamente, os problemas daí derivados. Na cidade teríamos, neste caso, a materialização da cidadania!

No caso brasileiro, ocorreu a materialização das relações sociais do tipo capitalista sem a vitória da cidadania burguesa. Ela se deu de forma enviesada, de forma atravessada, de forma incompleta. Por que incompleta? Porque na nossa sociedade penetraram as relações capitalistas - a mercadorização do ser social e do território - mas não inseriram plenamente a pessoa como cidadão, senhor de direito ou beneficiário do espaço público.

A realidade do capitalismo brasileiro está assentada na negação dos princípios da liberdade e da igualdade, que estruturam a cidadania. Aqui, ocorreu um reforço das desigualdades. Nós continuamos a ser um país do "você sabe com quem está falando?"; só que high-tech? A diferença não está somente na manutenção das desigualdades, mas no seu reforço, no seu caráter pós-moderno. Um país que continua tendo polícia para pobre, polícia para rico, transporte para pobre e transporte para rico, o mesmo ocorrendo com a educação ou justiça. Ainda se luta para que se viva numa cidadania burguesa.

Aqueles que seriam os elementos fundantes da cidadania - que vem junto com a lógica do capital - aqui não penetraram, e aí, como que se construiu essa modernidade urbana brasileira? Ela se construiu através da coisificação do ser social, através do mundo da mercadoria como forma básica de relações sociais - ambos no mercado de trabalho ou de consumo - e pela negação de direitos. 
Mercado de trabalho só tem esse nome porque o trabalho é uma mercadoria que está sendo comercializada e vendida no mercado. Essa coisificação do ser - atributo da ordem capitalista - numa sociedade capitalista e moderna foi recoberta tanto pela igualdade quanto pela liberdade, mesmo que formal.

$\mathrm{Na}$ sociedade brasileira, tais atributos, não viraram realidade concreta. $E$ aí, o que ocorre? O reforço das marcas e características anteriores ao período republicano, algumas ainda como permanências do período colonial. "República sem cidadania" poderia complementar o "Ordem e Progresso" da nossa bandeira criada em 1889. Ou cidade sem cidadãos!

Tomemos o transporte público, por exemplo: você pega um metrô em Londres e no mesmo vagão estão o operário, o presidente da empresa, o assessor do ministro, todo mundo está andando de metrô. O Brasil é o país do carro oficial! O carro que deveria ser de serviço para o órgão público se transforma em "carro oficial" com direito, inclusive a batedores, vias expressas, etc.

Nas sociedades onde ocorreu o avanço da cidadania, não existe carro oficial. Existe carro de serviço, você precisando de um veículo para o exercício de uma atividade pública, um carro público é requisitado. Mas não existe carro oficial. Tentem imaginar no Brasil a possibilidade do ministro ou secretário de Estado, ou mesmo de um município ter um carro oficial para utilizar nos afazeres do cargo e levá-lo a eventos oficiais e fazendo as compras do supermercado no carro dele...

\section{2 - A Questão Urbana}

A crise do "Estado do Mal-Estar brasileiro"14, manifesto na ausência da "cidadania qualitativa" 15 , se torna mais visível quando vemos a composição das grandes estruturas urbanas como a do Rio de Janeiro, de São Paulo ou de Belém do Pará e os conflitos daí derivados.

Por que isso se acirra? Primeiro que, ao aumentar a concentração populacional num território menor, as demandas, as crises e os atritos sociais se dão com muita maior profundidade e maior velocidade. Segundo, porque o próprio território - que é a referência

\footnotetext{
${ }^{14}$ Entendemos Estado do Mal-Estar a percepção que no caso brasileiro, ocorreu uma incompletude do Estado do Bem-Estar europeu,

${ }^{15}$ Por Cidadania Qualitativa entendemos a incorporação de vários direitos sociais, além do da participação eleitoral. A este respeito, ver Martins, José de Souza (2008). A Sociabilidade do Homem Simples, 2. ed., São Paulo: Contexto.
} 
nossa de existência social - é transformado com muito mais velocidade e intensidade alterando, dessa forma, a própria existência socioespacial.

Isto, porque a pessoa mora numa casa, numa rua, num bairro, que são as suas referências sociais e existenciais. Não mora nem no Estado nem na União. A gente sequer mora numa cidade. A cidade do Rio de Janeiro é uma das referências para a pessoa que com ela interage normalmente construída quando se encontra fora dela, visto que as pessoas se entendem enquanto bairros, localidades e comunidades. Este ser social vive na sua casa, no seu bairro, na sua rua e interage com os outros bairros na sua existência cotidiana, de forma fragmentada.

Nunca é demais lembrar que o processo de implantação das relações capitalistas na área urbana brasileira, é um processo extremamente destruidor das referências sociais locais, visto que a transformação do território urbano em mercadoria e viabilizador da efetivação das mercadorias, no Brasil, se deu sem a preservação do território público e das referências existências materializadas no patrimônio.

E mais, esse território - e aí é a outra face do estado do mal-estar social - não atende de forma minimamente igualitária com bens e serviços públicos de qualidade a todas as suas múltiplas territorialidades, gerando profundas desigualdades espaciais. Com relação a isso, basta olharmos indicadores acerca da coleta de lixo ou abastecimento de água por bairros ou localidades, por exemplo, que teremos uma visão bastante clara acerca da frequência e qualidade destes serviços públicos.

A desigualdade dos bens e serviços no território urbanizado brasileiro é algo surpreendente. Comparar a qualidade dos serviços públicos que são oferecidos nos bairros de classe média alta com aqueles de predomínio de habitações populares mesmo quando estes são territórios contíguos em que você sai de um e penetra no outro com muita rapidez - o que nos leva a percepção do quanto desiguais são as relações entre o Estado e os cidadãos.

Não por acaso, esses bairros de habitação popular, incluindo as favelas, vão ganhando identidade e - mesmo sendo irmão siamês do processo capitalista de apropriação urbana - e se diferenciam da "cidade maior" por um enorme conjunto de características.

[...] em suma, o que todos [os cientistas sociais] afirmam, é a forte identidade desses espaços, marcados não apenas por uma geografia própria, mas também pelo estatuto de ilegalidade da ocupação do solo, pela obstinação de seus moradores em permanecer na favela [...] e por um modo de vida cotidiano diferente, capaz de garantir sua identidade. A trajetória social típica dos jovens 
favelados seria o fracasso escolar e, pela atração exercida pelo poder e pelo dinheiro, o ingresso no "movimento" do tráfico de drogas [...]. ${ }^{16}$

Outro aspecto importante quando se observa as grandes cidades brasileiras no que tange a existência desses bairros populares é que, além da desigualdade na oferta de bens e serviços públicos, vem ocorrendo a perda dos tradicionais espaços de sociabilidade. O que são espaços de sociabilidade? Aquela coisinha que muitos de nós teve que era a pracinha do bairro, a vizinhança, o campinho de futebol, isso está acabando.

Ao contrário, a tendência da vida urbana contemporânea brasileira aponta para a construção de uma teia - aquilo que Ítalo Calvino chama as teias de Ariadne - de ligações entre os bairros de moradia e os do trabalho: grandes corredores de deslocamento de população que cortam o território urbano de forma cirúrgica, acabando com bairros e os transformando em locais de passagem, margeados ou circundados por favelas. Ao cortar, descaracteriza os bairros. O bairro vira o local de onde se sai; o local de passagem, mas ele perde a sua identidade e suas redes de sociabilidade, que são deslocadas para uma nova forma de espaços de sociabilidades - os shoppings centers - onde o que prevalece é o mundo da mercadoria.

Nesse sentido, o fenômeno urbano brasileiro, marcadamente rápido e intenso, aumentou muito o adensamento populacional nos bairros que apresentavam alguma infraestrutura urbana, mesmo que atendendo de forma desigual. A tendência vem sendo o de expansão das habitações populares precárias nos bairros mais bem aquinhoados de renda e serviços, o que garantiria em tese, emprego e atendimento público de alguma qualidade para os seus novos moradores.

Com isto, a clássica composição de bairros cêntricos - os melhores - e bairros populares vem sendo substituída. Isto implica em dizer que, nas últimas décadas, a periferia urbana e os processos de favelização avançaram nos bairros cêntricos rompendo a segregação espacial de antes. Riqueza e miséria, prédios de luxo e habitações populares passaram a coexistir num mesmo bairro e, muitas vezes, na mesma rua, embora não exclusivamente, com ênfase no caso do Rio de Janeiro.

Sem embargo, o adensamento urbano, num contexto de falência dos serviços públicos de transporte e de estímulo ao transporte privado de passageiros, passa a exigir a construção de grandes "redes de tráfego" e corredores de circulação que avançam

\footnotetext{
${ }^{16}$ Valladares, Lícia do Prado (2005). A Invenção da Favela: do mito de origem a favela.com, Rio de janeiro: FGV, p. 150.
} 
sobre os "vazios urbanos" que, na prática, eram utilizados pela população como espaços de sociabilidade.

Mais ainda, os territórios de sociabilidade que não foram ocupados ou pela especulação imobiliária ou pelas grandes obras viárias, acabam sendo "abandonados" pelo poder público. Todo espaço público "abandonado" começa a ser degradado e, ato contínuo, passa a ser dominado pelos segmentos sociais marginalizados que os transformam em territórios do medo.

Novamente pode-se observar a existência de áreas degradadas - as utilizadas pelas camadas populares - e áreas bem conservadas. Instala-se um círculo vicioso onde a área degradada é dominada pela criminalidade, que justifica ao próprio poder público para não recuperá-la, visto que "a população a destrói” ou que não tem como garantir a segurança para os seus agentes atuarem no sentido de recuperá-las e as manterem de forma condigna.

Uma das formas de entender esse processo de urbanização excludente está no próprio processo de transformação das cidades coloniais brasileiras em territórios sob a lógica do capital. Da mesma forma que a Revolução Burguesa no Brasil ocorreu - ou será que ainda ocorre? - ao longo do tempo, com avanços e recuos e com a persistência do arcaico com o moderno, vemos tal fenômeno ocorrer na constituição de um padrão urbano capitalista, o que aliás não poderia ser diferente.

\section{3 - o Homem Simples e a Violência Cotidiana}

A conjugação desse conjunto de fatores anteriormente elencados gera no homem simples com o seu senso comum, a sensação de que "eu não conheço mais o meu vizinho". O não se reconhecer nas redes de sociabilidade classicamente fortalece o "medo do outro", do estranho, particularmente quando o estranho me é diferente etnicamente, em termos de classe, de estética ou de comportamentos socioculturais. Independentemente de qualquer avaliação acerca da qualidade musical ou estética do funk, este sofre uma forte carga de estranhamento e preconceito inclusive de origem de classe, como ocorria com o samba nos primórdios do século XX.

Então, eu não vou mais pra pracinha porque eu tenho medo dos "novos moradores do bairro" que podem ser responsáveis pela "balbúrdia", pelo assalto, pelo tráfico ou mesmo, pela bala perdida. Quer dizer, eu diminuo a utilização dos espaços de 
sociabilidade; os poucos que restam. Eu não utilizo os poucos espaços de sociabilidade que restaram porque estão muito mal conservados ou porque eu tenho medo de usá-los, ou ainda, pelo "medo do vizinho que eu não conheço". Como a experiência internacional vem demonstrando, a articulação da degradação urbana, do estranhamento do outro e do medo da violência, leva-nos a nos isolarmos no interior de nossas casas, de nossas fortalezas. Afora isso, restam os "lugares seguros", os shoppings centers...

É nessa cidade que vive o homem simples com seu senso comum. Em tese, este homem simples ${ }^{17}$ - não se trata de uma questão de gênero - é aquela pessoa que pega 0 seu ônibus, o metrô, o trem ou a van e vai para o trabalho. Quer dizer é alguém que não é socialmente distinguido, "não é alguém", é ninguém!

É essa pessoa que chamamos de pessoa comum, de homem simples, que mora nessa cidade, que trabalha sob a superexploração do capitalismo periférico e sofre cotidianamente as contradições urbanas e carência de serviços públicos construindo e reproduzindo o senso comum.

Nunca é demais lembrar José de Souza Martins:

[...] É nesses momentos e situações de protagonismo oculto e mutilado dos simples, das pessoas comuns, dos que foram postos à margem da História, do homem sem qualidade que a sociedade propõe ao sociólogo suas indagações mais complexas, seus problemas mais ricos, sua diversidade teoricamente mais desafiadora [.... . $^{18}$

Continuando, "O senso comum é comum não porque seja banal ou mero e exterior conhecimento. Mas, porque é conhecimento compartilhado entre os sujeitos da relação social $[\ldots]^{19}$

Como essa pessoa se constrói como tal? Como ela vivencia o seu cotidiano? E como ela lida com a violência?

Primeiro, de forma alienada, quer dizer a pessoa não consegue construir uma consciência crítica do seu papel social. Ela "vive"! É como disse Chico Buarque: "todo dia ela faz tudo sempre igual, me sacode às seis horas da manhã". É essa a vida do homem simples. Está certo que não dá nem tempo para ele construir consciência crítica: ele tem que ganhar o pão, ele tem que lutar, ele tem que correr para não perder o emprego. Ela sofre um processo contínuo de agressão, é aquilo que chamamos de violentação da cotidianidade urbana.

\footnotetext{
17 Tomo emprestadas as reflexões de José de Souza Martins.

${ }^{18}$ Martins, J. (2008). Op. Cit, p. 11-12.

${ }^{19}$ lbidem, p. 54.
} 
Isso porque como foi implantado o estado do "mal-estar social". O cidadão quando sai de casa, pega um transporte ruim, cheio, perigoso; que atrasa, que é caro, se insere num mundo que o agride, que o violenta. Preocupado com o fato de que, se chegar atrasado o patrão manda embora, ele pega a van que não tem segurança e que se ocorrer uma colisão ele vai para a emergência de hospital público, etc. e tal. Aí ele vai chegar ao trabalho e, na hora de almoçar, a comida é ruim e cara; e ele vai suportando "todo dia ele faz tudo sempre igual, me sacode às seis horas da manhã". Sem a capacidade de construir a consciência do seu papel social e violentado na sua cotidianidade, ele só consegue construir a razão prática, ou seja, como sobreviver a cada dia, ele não consegue construir uma razão crítica ${ }^{20}$ ou construir um projeto de vida.

O que marca essas pessoas é a quase que total incapacidade de construção de um projeto de vida. Ou, o que é mais sério, o projeto de vida se confunde com o projeto de sobrevivência. Ele constrói esse projeto pragmático de vida pelas referências que ele tem. A principal referência é a de vencer na vida - o ser alguém na vida - é ter mercadorias que o distingam social. Seu projeto de vida, construído a partir do mundo da mercadoria e não a partir da sua existência, ou da sua qualidade de vida ou da sua felicidade, pois isso está fora do sistema. Dentro do sistema e na lógica do mundo da mercadoria, o carro, o apartamento, a roupa, são os grandes sinais de quem alguém venceu na vida.

Como somente isso não basta devido à incompletude do ser social no mundo da mercadoria, as suas emoções e sentimentos não são saciados. Este homem simples só consegue "ver" como alternativa para o seu cotidiano de vida onde é tratado de forma desigual, através do às formas básicas de sociabilidade com ações reativas, como o atrito das relações sociais avançando para o exercício da violência, de forma análoga àquela já apontada por Engels em meados do século XIX, e não, de uma forma cidadã.

Complementando este quadro, ocorre no plano da sensibilidade por parte desse homem simples que alguma coisa mudou no seu cotidiano. Já não pode mais usar a praça e os outros locais de sociabilidade. Os bairros periféricos - as favelas - antes distantes do "seu bairro" e que ele podia se afastar ou negar, agora estão no seu próprio bairro ou sua rua. Os vizinhos ele já não os identifica.

Considerando tais coisas, como o homem simples percebe e convive cotidianamente, através do sendo comum, a sua inserção na sociedade e na sua relação

\footnotetext{
${ }^{20}$ A respeito das diferenças entre razão prática e razão crítica, veja Marcuse, Herbert (1996). "Algumas Implicações Sociais da Tecnologia Moderna". In Revista Praga, São Paulo, n.1, set/dez. 1996
} 
com os outros? As formas de relação do sujeito simples com o outro no cotidiano além de mediadas pelas mercadorias (carro, casa, roupa, celular) que the garantiria um autopoder e uma respeitabilidade social, o faz retornar àquelas relações agressivas e violentas, não mediadas pelo mundo da lei, não mediadas pelo mundo da ordem, não mediadas pelo mundo da civilidade. E aí, como ele não consegue construir a civilidade ou a perdeu, essa relação vai se dar de forma da violência explícita. Então esse homem simples vai viver a violência e se tornar um homem violento!

Estamos falando de uma violência "poli fronte', dissimulada nas estatísticas policiais, e que por vezes foge ao foco dos estudiosos do tema e que, também podem ser interpretadas como linguagens sociais reativas à cotidianidade urbana contemporânea.

A violência dos movimentos sociais é uma delas. Chega um belo dia, o trem atrasa, ele vai lá e quebra o trem. Ele não está pensando que no dia seguinte vai ser pior porque o trem vai continuar ruim, aliás, pior porque não vai ter nem aquele trem. Mas, ele põe fogo no ônibus, ele destrói o supermercado, ele canaliza o seu potencial de agressividade para aqueles que simbolizam a sua violência diária. Ele lincha um suposto bandido. Ora, quem lincha não é um facínora é uma pessoa absolutamente comum.

Outra forma de violência urbana pode ser visto através das pichações dos espaços públicos e privados, além de depredações de equipamentos urbanos, que é ele mesmo quem utiliza. Quem utiliza o trem suburbano degradado, ou a praça, é o homem simples, o pobre, visto que o rico tem seu próprio carro, tem piscina em casa ou frequenta um clube.

A violência doméstica realizada pelo homem simples agredindo a mulher, os filhos, os idosos, só muito recentemente começou a aparecer nas estatísticas oficiais e ser objeto de algumas ações governamental, dentre outras. A lista pode ampliar se considerarmos outros crimes como as ameaças e lesões corporais ocorridas entre vizinho devido a razões fúteis são facilmente presentes nos bairros populares.

\section{Referências}

Abreu, Mauricio de Paiva (2010). Geografia Histórica do Rio de Janeiro, Rio de Janeiro: Andrea Jacobson.

Barros, José D’Assunção (2007). Cidade e História, Petrópolis: Vozes. 
Bresciani, Maria Stella (2002). "Cidade e história". In Oliveira, Lucia Lippi (Org.) (2002). Cidade: história e desafios, Rio de Janeiro: Ed.FGV.

Carlos, Ana Fani (2011). "Da Organização à Produção do Espaço no Movimento do Pensamento Geográfico". In Carlos, Ana Fani et al. (Orgs.) (2011). A Produção do Espaço Urbano, São Paulo: Contexto.

Engels, Friedrich (1975). A Situação da Classe Trabalhadora na Inglaterra, Porto: Apontamento.

Ferreira, Sandra Cristina (2008). "Urbanização e Rede Urbana Brasileira: Orientação Teórica e Metodológica Preliminar". In I Simpósio de Pós-Graduação em Geografia do Estado de São Paulo, Rio Claro: UNESP.

Fridman, Fania e Abreu, Maurício (2010). Cidades Latino-Americanas, Rio de Janeiro: FAPERJ/Casa da Palavra.

Harvey, David (2006). A Produção Capitalista do Espaço, 2. ed., São Paulo: Annablume/HUCITEC/PMS.

Holanda, Sergio Buarque (1987). Raízes do Brasil, 19. ed., Rio de Janeiro: J. Olympio.

Lefebvre, Henri (1999). A Cidade do Capital, Rio de Janeiro: DP\&A.

Martins, José de Souza (2008). A Sociabilidade do Homem Simples, 2. ed., São Paulo: Contexto.

Marx, Karl e Engels, Friedrich (2007). A Ideologia Alemã, São Paulo: Boitempo.

Pesavento, Sandra Jatahy (1999). O Imaginário da Cidade, Porto Alegre: UFRGS.

Pinheiro, Eloisa Petti (2002). Europa, França e Bahia: Difusão e adaptação de Modelos Urbanos (Paris, Rio e Salvador), Salvador: UFBA.

Prado Jr., Caio (1947). Evolução Política do Brasil, 2. ed., São Paulo: Brasiliense.

Valladares, Lícia do Prado (2005). A Invenção da Favela: do mito de origem a favela.com, Rio de janeiro: FGV.

Recebido para publicação em outubro de 2012.

Aprovado para publicação em dezembro de 2012. 